\title{
ADVANCED CONCEPTS REPORT ON THE DETECTION OF XENON WITH A MINIATURE WHOLE AR SAMPLER CAPABLE OF EXTENDED OPERATING TIMES
}

\author{
B.G. Motes \\ G.J. MoManus \\ S.K. Bird \\ S.J. Femandez
}

July 1993

(W) Westinghouse Idaho

PREPARED FOR THE DEPARTMENT OF ENERGY IDAHO OPERATIONS OFFICE UNDER CONTRACT DE-AC07-84ID12435 


\begin{abstract}
Many monitoring activities require the collection of whole air samples over an extended time interval without loss or concentration of any atmospheric constituents. Described is the development and laboratory testing of a whole air sampler capable of collecting a 100 liter sample over a period of 0.63 days. The sampler has an empty weight of $7.79 \mathrm{~kg}$ and an overall size of $20.8-\mathrm{cm} \times 20.8-\mathrm{cm} \times 66.1-\mathrm{cm}$. The conceptual design for the development of smaller, higher-performance whole air samplers is also reported.
\end{abstract}




\section{Introduction}

In response to a customer need, Westinghouse Idaho Nuclear Company (WINCO) personnel have developed and tested in the laboratory a miniature whole air sampler capable of collecting a 100 liter sample and retaining cryogenic temperatures for an extended period of time. The sampler has the ability to collect a highly compressed gas sample without concentration of condensible gases. This permits a large number of gas constituents to be analyzed from a single sample, even when analytes vary widely in their boiling points.

The principle of operation of the sampler is the collection of the whole air sample into a previously evacuated sample cylinder. The sample cylinder is maintained at liquid nitrogen temperatures through the use of a reservior.

Design criteria for the miniature whole air sampler include the following characteristics:
1) A total sample volume of 100 liters at STP.
2) No concentration or loss of any atmospheric constituents.
3) Operation without electrical power.
4) An empty weight of less than $10 \mathrm{~kg}$.
5) As small as size as possible.
6) An extended sampling lifetime.

\section{Sampler Description}

The cryogenic air sampler, shown in Figure 1, is constructed in-house from commercially available components. Specific components of the sampler, numbered in the same manner as Figure 1, are as follows:

1) A Matheson $24.92-\mathrm{cm}$ tall $\times 9.04-\mathrm{cm}$ wide rotameter equipped with a flow control valve, a 603 tube, and glass and stainless steel floats for measurement of sample flowrate.

2) A Whitey 20K Series No. SS-20KM4-F4 rated 6000 psi forged body stainless steel shutoff valve with a $4.0-\mathrm{mm}$ orifice and dimensions of $5.4-\mathrm{cm} \times 5.8-\mathrm{cm}$ for sample introduction and isolation. The valve is lined to the rotameter by a $14.4-\mathrm{cm}$ length of $0.63-\mathrm{cm}$ stainless steel tubing.

3) A 5.4-cm $\times 2.7-\mathrm{cm}$ female tee joint manufactured by CAJON (No. SS-4-T) with a pressure rating of 6900 psig. 


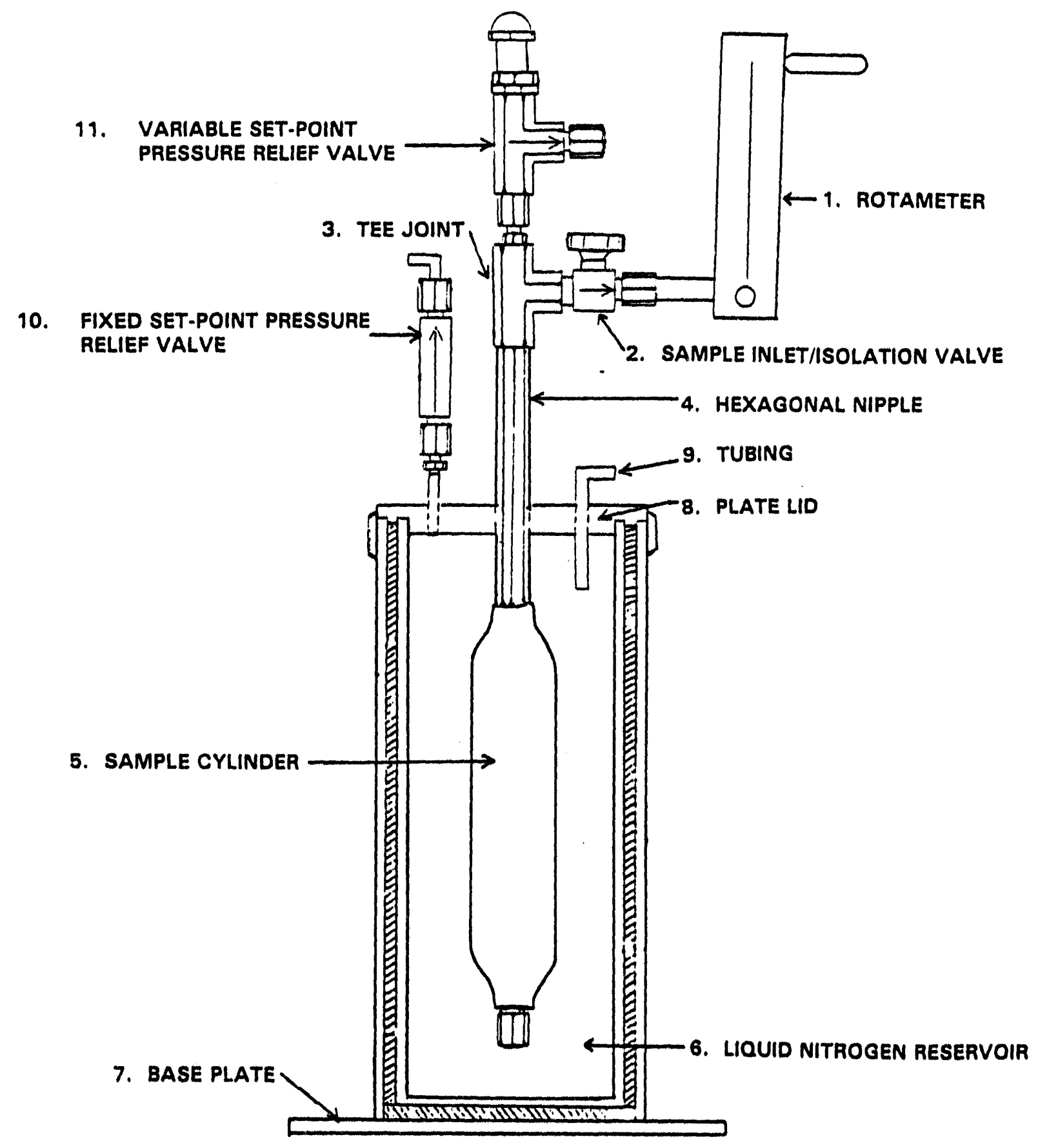

FIGURE 1. Passive Cryogenic Sampler 
4) A 10.2-cm long stainless steel hex long nipple manufactured by CAJON (No. SS-4-HL.N) with a pressure rating of 7500 psig.

5) A WHITEY (No. 316L-50DF4-300) 300-cc internal volume stainless steel cylinder for the collection of the whole air sample. Dimensions of the sample cylinder are $23.5-\mathrm{cm}$ long $\times 5.1-\mathrm{cm}$ outside diameter $\times 0.240-\mathrm{cm}$ wall thickness. The pressure rating of the cylinder is $5000 \mathrm{psig}$ and the DOT classification is $3 A-5000$. The end of the cylinder near the base of the sampler is closed by a male stainless steel pipe plug.

6) An approximately 5.0 liter internal volume liquid nitrogen reservoir for cooling of the sampler cylinder. The 300-cc internal volume stainless steel sample cylinder is enclosed by a $6.7 \mathrm{~cm}$ diameter inner chamber for holding liquid nitrogen. The liquid nitrogen reservoir is contained by a durable, light weight, high-strength aluminum shell. The liquid nitrogen is adsorbed on a filling. This allows the liquid nitrogen to be released in a gaseous phase providing cooling capabilities over an extended interval of time.

The nominal static holding time for the reservoir is 32 days. However, this is affected by numerous variables including the nature of the contents, atmospheric conditions, and container history. An arbitrary, reference-only value for container performance under operating conditions is the static holding time divided by 1.6. In this case, this value is 20 days.

7) An $11-\mathrm{cm}$ diameter by $3.5-\mathrm{cm}$ thick polypropylene lid for the liquid nitrogen reservoir. A groove in the lid allows pressure relief venting of the liquid nitrogen reservoir.

8) A NUPRO (No. SS-4R3A5-316) variable setpoint pressure relief valve for venting the sample cylinder. The setpoint range of the valve is $5000-6000$ psi and is determined by a spring. The spring has been adjusted for venting at $5000 \mathrm{psi}$. The valve is $8.5-\mathrm{cm}$ in length and is mounted above the tee joint. The relief valve was incorporated as a safety precaution in the event of excessive pressure buildup in the sample cylinder. In the event of such an occurrence, the pressure relief valve only vents the pressure in excess of the setpoint prior to reclosure. As a result, only a small portion of sample is lost. 
9) A 6.3-cm long insulating collar extending beneath the polypropylene lid and covering the hex long nipple and the upper portion of the sample cylinder. This insulating lid is an important component of the unit as it limits heat transfer through the lid and prevents the nipple from freezing.

Considered as an operating unit, the sampler has a maximum height of $66.1-\mathrm{cm}$ and a length and width of $20.8-\mathrm{cm}$. The empty weight of the unit is $7.79-\mathrm{kg}$. When filled with 5 liters of liquid nitrogen the unit weighs $11.79-\mathrm{kg}$. The static evaporation rate of the liquid nitrogen is 0.16 -liters/day. The evaporation rate during sotual use is in the process of being determined. 


\title{
EXPERIMENTAL TESTING AND RESULTS
}

\author{
Sampler Operation
}

Operation of the sampler consists of preparation of the sampler, collection of the sample, and transfer of the sample to a sample storage container for subsequent analysis.

The sampler is prepared by filling the liquid nitrogen reservoir and evacuating the cylinder. The liquid nitrogen reservoir is filled, the opening in the neck is covered, and the vessel is allowed to stand for 30 minutes. This process is repeated at least 4 times, until there is minimal change in the volume of liquid nitrogen after $\mathbf{3 0}$ minutes. While this is being done, the cylinder is being evacuated. After pumping for 10 minutes, a heat gun is used to warm the sample cylinder for 20 minutes. Pumping is continued for at least another 1.5 hours after heating. The sample cylinder is then isolated by closing the sample induction valve.

After the sample cylinder has been evacuated, it is cooled by placing it in a vessel filled with liquid nitrogen for at least 20 minutes. This vessel is refilled with liquid nitrogen as necessary to maintain the sample cylinder at a temperature of $77^{\circ} \mathrm{K}$. Maintaining the sample cylinder at the temperature of liquid nitrogen is required to keep reduced pressure in the sample cylinder and to provide the driving force for collection of the whole air sampler. The sample cylinder must be precooled before being placed in the sampler reservoir. If this is not done, the small amount of liquid nitrogen that has not been adsorbed will be expended in cooling the sample cylinder. This will reduce the size of sample that can be collected to approximately 21 liters.

By weighing the unit before and after collecting a sample and subtracting the weight of the sample collected; an estimate of the amount of liquid nitrogen necessary for a collection has been made. This amount is approximately 710 grams. 
SAMPLE FLOWRATE, VOLUME, LIFETIME, AND PRESSURE MEASUREMENTS

A series of 2 tests were performed in the limited time available. The results of these tests are shown in Tables 1 and 2.

As seen from the test data, the initial flowrate is in excess of 3 liters/minute and decays to as low as 0.32 liters/minute at the end of 90 minutes. A sampling interval of $83-90$ minutes is sufficient to collect a 100 liter sample. The pressure of the sample cylinder is between 4900 and 5000 psi. The pressure relief valve prevents a sample greater than 5000 psi being collected. 


\section{IABLE 1}

Flowrate Measurements of Miniature Whole Air Sampler

Cooling Duration Prior to Test: 15 hours 15 minutes

Length of Sample Collection: 1 hour 30 minutes

Sample Pressure: 5500 psi

Volume of Sample: 112.27 liters

Flowrate

Liters/Minutes

4.34

3.40

2.78

2.52

2.44

2.38

2.38

2.04

1.86

1.72

1.36

1.24

1.14

1.04

0.92

0.86

1.04

0.86

0.72

0.62

0.54

0.46

0.38

0.32
Time in

Minutes

$$
0.25
$$

0.50

1

2

3

4

5

10

15

20

25

30

35

40

45

50

55

60

65

70

75

80

85

90 


\section{IABLE 2}

Flowrate Measurements of Miniature Whole Air Sampler

Cooling Duration Prior to Test: 15 hours

Length of Sample Collection: 1 hour 23 minutes

Sample Pressure: $4900 \mathrm{psi}$

Volume of Sample: 100.02 liters

\section{Flowrate \\ Liters/Minutes}

3.54

2.42

1.92

1.54

1.48

1.62

1.74

1.62

1.62

1.54

1.52

1.52

1.48

1.28

1.16

1.08

0.94

1.16

1.36

1.32

1.22

1.16

1.08

0.96

0.86

0.74

0.66
Time in

Minutes

\subsection{5}

0.50

1

2

3

$0.25^{\circ}$

0.50

1

2

3

4

5

10

15

20

25

30

35

40

45

50

55

60

65

70

75

80

a. Initial collection begun without insulating collar after 12 hours cooling time. Collection terminated after 3 minutes due to insufficient flowrate. Insulating collar installed and system cooled for 3 hours before resuming test. 


\section{FUTURE DEVELOPMENT}

From this study it has been determined that approximately 710 grams of liquid nitrogen is necessary to collect a 100 liter sample. Therefore, an important physical parameter has been determined for future attempts to build smaller samplers. By constructing un enhanced liquid nitrogen reservoir, with tho absorbent medium in direct contact with the sample cylinder, it may be possible to eliminate all liquid nitrogen that is not adsorbed and eliminate the need to add more liquid nitrogen prior to sampling. If liquid nitrogen can be added prior to sampling, there is no reason to suppose that a sample could not be collected with the current system after a longer interval than 15 hours 15 minutes. 

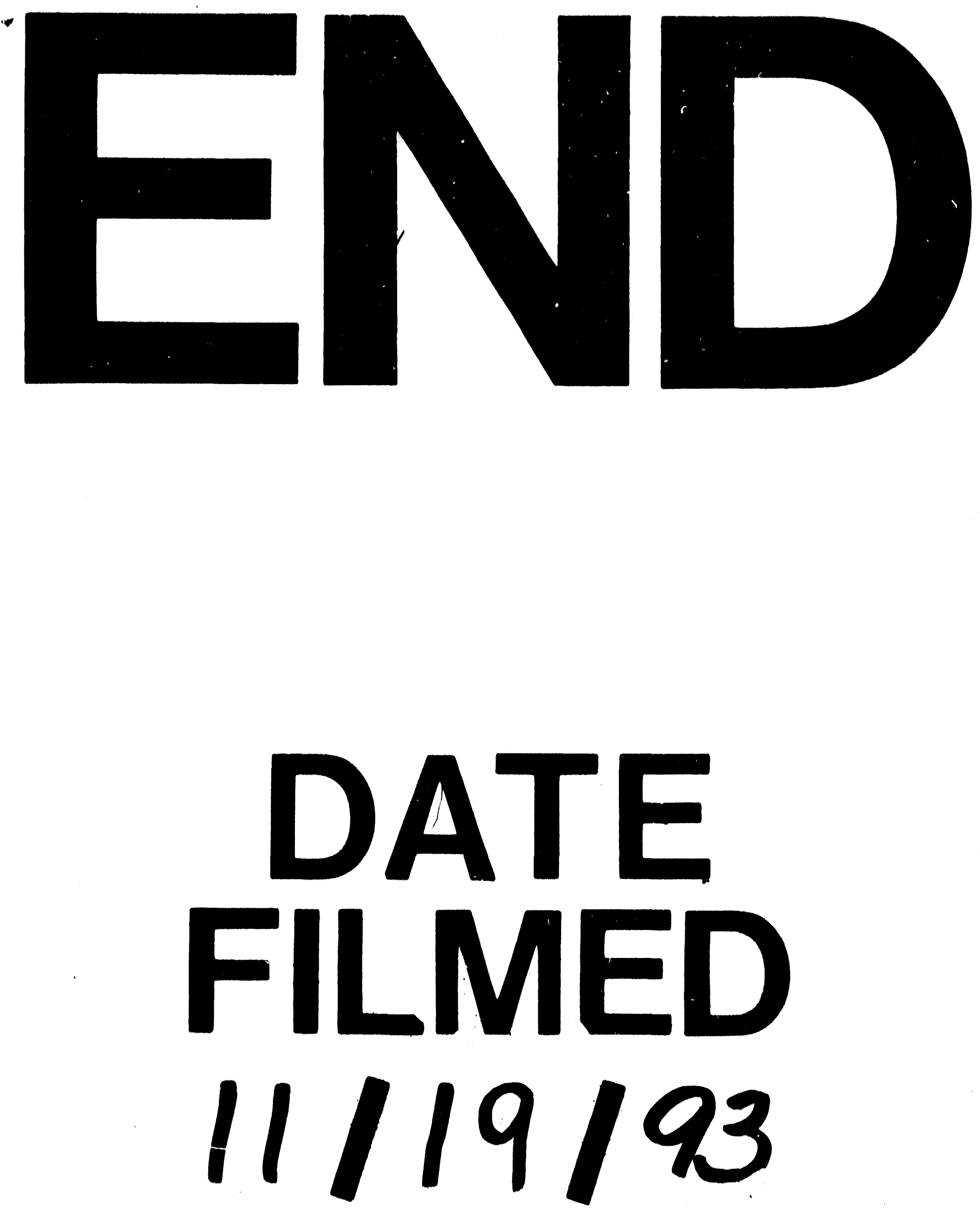